\title{
Effect of recycled gas temperature on coal combustion in oxygen blast
}

\author{
furnace \\ Zhenfeng Zhou ${ }^{\mathrm{a}, *}$, Guang Wang ${ }^{\mathrm{b}}$ \\ State Key Laboratory of Advanced Metallurgy, University of Science and Technology Beijing. \\ No.30, Xueyuan Road, Haidian District, Beijing City, China. \\ aE-mail: zhouzhenfeng1989@sina.com, 15311935569. \\ bE-mail: wangguang@ustb.edu.cn.
}

Keywords: oxygen blast furnace; coal; burnout; recycled gas

Abstract: The oxygen blast furnace (OBF) is a new ironmaking technology. The coke rate and carbon dioxide emission can be decreased greatly in the OBF process. In the OBF process, the room-temperature oxygen is blown and the preheated top gas of $\mathrm{CO}_{2}$ stripped is recycled into the furnace. The recycled gas has various positive and negative effects on coal combustion. To further understand the effect of recycled gas on coal combustion and increase the coal burnout as much as possible, it is necessary to carry out some investigations. In the study, a three dimensional coal combustion model is developed to simulate the oxygen/coal lance-blowpipe-tuyere-raceway of a OBF. The effect of recycled gas temperature was investigated.

\section{Introduction}

The oxygen blast furnace (OBF) is a new ironmaking technology. In theory, the coke rate and $\mathrm{CO}_{2}$ emission can be reduced greatly. [1] In the OBF process, there are the lower (hearth) and upper (shaft) tuyeres. For the hearth tuyere, the room-temperature oxygen is blown into the blast furnace, and the pulverized coal is injected. The preheated top gas of $\mathrm{CO}_{2}$ stripped is recycled into the blast furnace by the hearth and shaft tuyeres.

Top gas of $\mathrm{CO}_{2}$ stripped injection is the main characteristic of the OBF process. The recycled gas contains much reducing gas $\left(\mathrm{CO}+\mathrm{H}_{2}\right)$. The reducing gas can rapidly react with oxygen and release much heat. This is very beneficial to preheating and devolatilization of coal particles and ensures the entire coal combustion process. However, the combustion of recycled gas competes for oxygen with coal particles. To further understand the effect of recycled gas on coal combustion and further increase the coal burnout as much as possible, further studies need to be carried out.

The reactions in the raceway of the OBF are complex, and the environment is harsh. Therefore, it is very difficult to carry out a trial of pulverized coal injection (PCI) in the OBF. However, computational fluid dynamic (CFD) provides a new method for the investigation of PCI in BF. Many investigations on the coal combustion in blast furnace (BF) using CFD have demonstrated its great reliability and superiority.[2-4] Therefore, in this study, the effect of recycled gas temperature on coal combustion in the $\mathrm{OBF}$ is investigated using CFD.

\section{Mathematical Model}

The gas-particle flow and coal combustion in the tuyere and raceway region were calculated 
based on the framework of software package ANSYS-FLUENT. The mathematical formulation is described elsewhere in details.[5-7]

\section{Geometry and Operating Condition}

A test OBF of $120 \mathrm{~m}^{3}$ will be built at a steel company in China based. The main operation parameters of the OBF are summarized in Table 1.

The model simulates the coal lance-blowpipe-tuyere-raceway of the TBF and oxygen/coal lance-blowpipe-tuyere-raceway of the OBF. The detailed parameters of the models are shown in Fig. 1. The raceway is designed as a tube of $700 \mathrm{~mm}$ long with a divergence angle of $3^{\circ}$ referring to others.[3]

Table 1 Main blast parameters of OBF

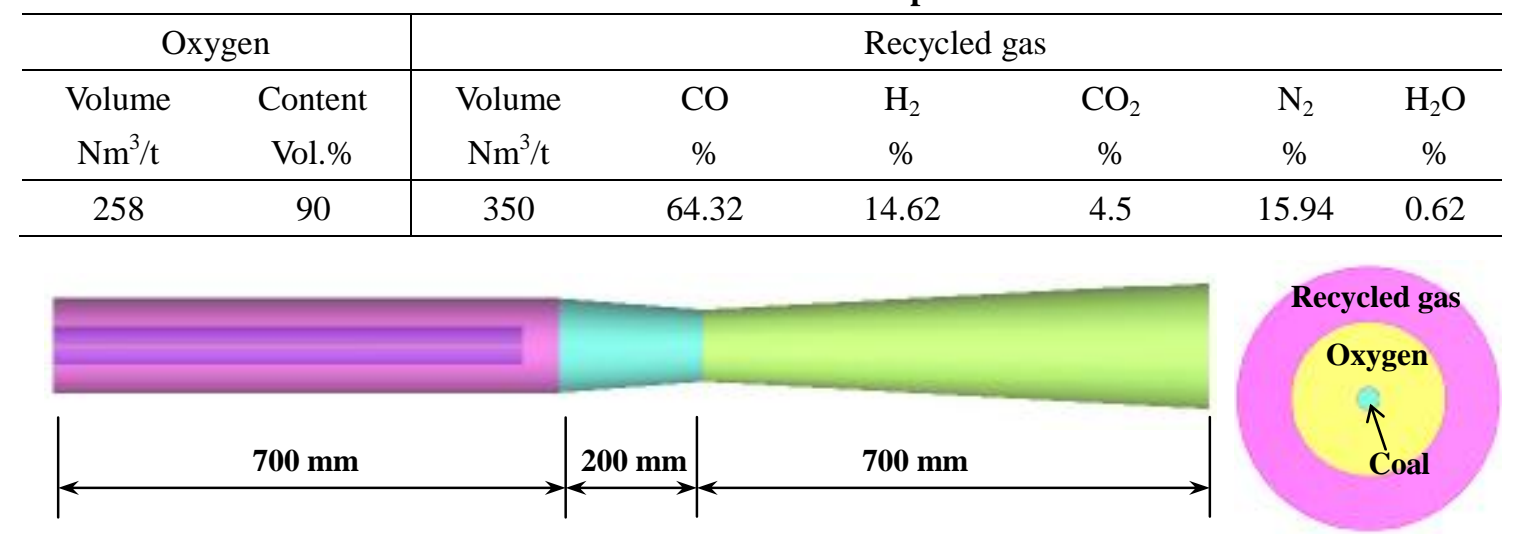

Fig. 1. Geometry of the model

\section{Results and Discussion}

\section{Model Validation}

CFD has been extensively used for the simulation of coal combustion in the blast furnace, and the reliability of this approach has been fully proved.[2-4] Before investigating the coal combustion in OBF, some investigations on coal combustion in the TBF using CFD are carried out. The simulation results and phenomena are very similar to those of others.[5,7,8] These comparisons have fully illustrated the reliability of this model. 


\section{Effect of recycled gas temperature}

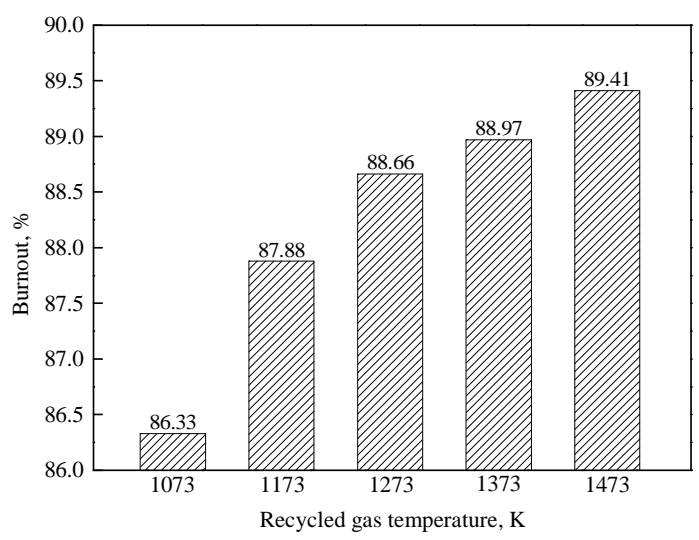

Fig. 2 Effect of recycled gas temperature on final coal burnout

Fig. 2 shows the effect of recycled gas temperature on the final coal burnout. In general, the final coal burnout increases with increase of the recycled gas temperature. When the recycled gas temperature increases from $1073 \mathrm{~K}$ to $1473 \mathrm{~K}$, the coal burnout increases from $86.33 \%$ to $89.41 \%$, with an increase of $3.08 \%$. With increase of recycled gas temperature, the combustion rate of recycled gas increases, and more heat is released. This is very beneficial to the devolatilization and char combustion. However, the combustion of recycled gas competes for oxygen with the coal particles. The common interaction of pros and cons may be the main reason for slight increase of the final burnout with the increase of recycled gas temperature.



Fig. 3 Effect of recycled gas temperature on coal burnout at different positions

To further understand the effect of recycled gas temperature on coal combustion, the coal burnout of different recycled gas temperature at different positions is investigated, as shown in Fig. 3. The coal combustion mainly undergoes two processes: the devolatilization and char combustion. The devolatilization process is mainly related with temperature. When the temperature of coal particles reaches the vaporization temperature, the devolatilization process will start. Significant devolatilization starts at about $600 \mathrm{~K}$.

In OBF, the heat of initial coal combustion stage is mainly from the combustion of recycled gas. With increase of recycled gas temperature, the reaction rate rapidly increases, and more heat is released. This is very beneficial to the devolatilization process. Therefore, in the upstream of the coal plume, the coal burnout obviously increases with increase of the recycled gas temperature. In the initial stage of char combustion, the oxygen is adequate, and the char can rapidly react with the oxygen. In other words, it means that the coal combustion process is advanced, and the coal burnout will increase significantly. Before the distance of $0.7 \mathrm{~m}$, the increasing rate of the coal burnout gradually increases. At the distance of $0.7 \mathrm{~m}$, the coal burnout increases from $27.36 \%$ to $54.25 \%$, 
with an increase of $26.89 \%$, when the recycled gas temperature increases from $1073 \mathrm{~K}$ to $1473 \mathrm{~K}$. After the distance of $0.7 \mathrm{~m}$, the increasing rate of the coal burnout gradually decreases. This is because with increase of recycled gas temperature much combustion of coal particles and recycled gas consumes more oxygen in the upstream of the coal plume; the coal combustion rate decreases due to the lack of oxygen in the downstream of the coal plume. At lower recycled gas temperature, less oxygen is consumed in the upstream of the coal plume; in the downstream of the coal plume, the coal burnout continues to rapidly increase, making up for the hysteresis in the upper part.

\section{Conclusions}

The effect of recycled gas temperature on coal combustion is complex. With increase of recycled gas temperature, the increasing rate of the coal burnout firstly increases and then decreases along the centerline of the tuyere. The maximum increase can reach $26.89 \%$ when the recycled gas increases from $1073 \mathrm{~K}$ to $1473 \mathrm{~K}$. The combustion rate of recycled gas increases with increasing recycled gas temperature, and more heat is released. However, the coal combustion rate decreases due to the lack of oxygen at the end of the raceway.

\section{References}

[1] Q. Minshen and Z. Yuting: Ironmak. Steelmak. Vol. 15 (1988), p. 287.

[2] A. T. Wijayanta, M. S. Alam, K. Nakaso, J. Fukai, K. Kunitomo and M. Shimizu: Fuel Process. Technol. Vol. 117 (2014), p. 53.

[3] Y. S. Shen, D. Maldonado, B. Y. Guo, A. B. Yu, P. Austin and P. Zulli: Ind. Eng. Chem. Res. Vol. 48 (2009), p. 10314.

[4] Y. S. Shen, A. B. Yu, P. R. Austin and P. Zulli: Powder Technol. Vol. 223 (2012), p. 27.

[5] Z. Zhou, Y. Liu, G. Wang, X. She, Q. Xue and J. Wang: ISIJ Int. Vol. 57 (2017), p. 279.

[6] Y. S. Shen, B. Y. Guo, A. B. Yu, P. R. Austin and P. Zulli: Fuel Vol. 90 (2011), p. 728.

[7] Z. Zhou, H. Huo, G. Wang, Q. Xue, X. She and J. Wang: Steel Res. Int. Vol. 88 (2017), p. 1.

[8] Z. Zhou, Q. Xue, C. Li, G. Wang, X. She and J. Wang: Appl. Therm. Eng. Vol. 123 (2017), p. 1096. 